\title{
O exercício do magistério superior e o direito educacional brasileiro
}

\author{
Horácio Wanderlei Rodrigues ${ }^{1}$
}

\begin{abstract}
Sumário: Introdução; 1. A obrigatoriedade da pós-graduação; 2. A incidência temporal da exigência de titulação acadêmica; 3 . A abrangência da expressão "preparação para o exercício do magistério superior"; 4. A exigência específica de percentual de titulação para os docentes das universidades; Conclusão; Referências.
\end{abstract}

Resumo: O objeto do artigo é a análise das exigências existentes no Brasil para o exercício do magistério superior. A análise é realizada fundamentalmente no âmbito normativo, partindo da LDB e, quando necessário, buscando nos pareceres e resoluções do CNE e nos Decretos do MEC as regulamentações e conceituações específicas. A conclusão central é no sentido de que o Direito Educacional exige que todos os docentes do ensino superior brasileiro possuam pósgraduação e que essa deve incluir necessariamente conteúdos voltados à formação pedagógica.

Palavras-chave: ensino superior; pós-graduação; Titulação acadêmica; magistério superior; formação acadêmica.

\begin{abstract}
The object of this article is the analysis of existing requirements in Brazil for the exercise of teaching higher. The analysis is carried out primarily under normative, based on the LDB and, when necessary, seeking the opinions and resolutions of the CNE and the decrees of the MEC rules and specific conceptualizations. The conclusion is central to the Education Law requires all teachers of higher education have Brazilian post-graduate and that this must necessarily include content focused on teacher training.
\end{abstract}

Keywords: higher education; post-graduation; academic degree; teaching higher; education.

1 Doutor em Direito pela UFSC, instituição da qual é Professor Titular, lecionando no Curso de Graduação (Metodologia da Pesquisa em Direito) e no Curso de Pós-Graduação, nos Programas de Mestrado e Doutorado (Epistemologia Jurídica e Fundamentos e Metodologia do Ensino e da Pesquisa em Direito). É também professor convidado para cursos de Pós-Graduação em diversas IES brasileiras. Escreveu os livros "Ensino jurídico: saber e poder", "Ensino jurídico e direito alternativo", "Acesso à justiça no direito processual brasileiro", "Novo currículo mínimo dos cursos jurídicos", "Ensino do Direito no Brasil: diretrizes curriculares e avaliação das condições de ensino" (esse último em conjunto com Eliane Botelho Junqueira) e "Pensando o Ensino do Direito no Século XXI: diretrizes curriculares, projeto pedagógico e outras questões pertinentes"; organizou as coletâneas "Lições alternativas de direito processual", "Solução de controvérsias no Mercosul", "O Direito no terceiro milênio" e "Ensino Jurídico para que $(m)$ ?". Publicou também dezenas de artigos em coletâneas e revistas especializadas, em especial sobre Teoria do Processo e Processo Constitucional, Direito Educacional, Ensino do Direito e Metodologia do Ensino e da Pesquisa. Membro da Comissão do Provão de 1996 a 1998 e avaliador do INEP/MEC. 


\section{Introdução}

A LDB de dezembro de 1996 trouxe, em seu artigo 66, norma de extrema importância para que se possa pensar um ensino superior de qualidade no país. Segundo seu texto "A preparação para o exercício do magistério superior far-se-á em nível de pós-graduação, prioritariamente em programas de mestrado e doutorado". ${ }^{2}$

O presente artigo objetiva realizar, em breves palavras, a análise dessa norma, em quatro níveis:

a) a obrigatoriedade da formação em nível de pós-graduação, para fins de exercício do magistério superior;

b) a incidência temporal dessa exigência de titulação acadêmica;

c) a abrangência dessa preparação e seus efeitos sobre as grades curriculares dos cursos de pós-graduação; e

d) as exigências específicas constantes na legislação relativamente às universidades.

O que se buscará nas linhas que seguem é, portanto, extrair o seu conteúdo a partir de uma visão técnica, em nível jurídico, e finalística, em nível da proposta pedagógica contida na nova lei que rege a educação brasileira.

\section{A obrigatoriedade da pós-graduação}

Antes de ingressar na análise da questão da obrigatoriedade da formação em nível de pós-graduação, para fins de exercício do magistério superior, é importante recuperar pelo menos dois momentos históricos no que se refere a essa exigência:

a) como ela se dava quando da criação dos cursos superiores no Brasil; e

b) como ela se dava no sistema anterior à atual LDB.

Como se sabe, a história do ensino superior no Brasil se inicia com a criação de dois cursos de "Ciências Jurídicas e Sociais", um na cidade

2 BRASIL. Lei $n^{\circ}$ 9.394/1996 (LDB). 
de São Paulo e outro na cidade de Olinda, através de Lei de 11 de agosto de 1827. Essa lei continha, em seu artigo $9^{\circ}$, a seguinte norma:

Os que freqüentarem os cinco anos de qualquer dos Cursos, com aprovação, conseguirão o grau de Bacharéis formados. Haverá também o grau de Doutor, que será conferido àqueles que se habilitarem com os requisitos que se especificarem nos Estatutos, que devem formar-se, e só os que o obtiverem, poderão ser escolhidos para Lentes.3 (grifos do autor).

Como se pode perceber do texto transcrito, já quando da criação dos primeiros cursos superiores no país, existia a previsão legal para a concessão do grau de doutor, sendo o magistério superior privativo daqueles que o obtivessem.

No sistema anterior ao da LDB vigente, a matéria relativa às exigências para o exercício do magistério superior encontrava-se na Resolução n 20/1977 do Conselho Federal de Educação (CFE). Segundo essa legislação, em seu artigo $4^{\circ}$ :

A qualificação básica e indispensável do docente será demonstrada pela posse de diploma de graduação expedido por curso superior em que se ministre matéria ou disciplina idêntica ou afim, pelo menos no mesmo nível de complexidade daquela para a qual é indicado. ${ }^{4}$

Essa exigência básica também era suprida pela formação em nível de pós-graduação stricto sensu com área de concentração na matéria ou disciplina para a qual o docente era indicado. A pós-graduação também retorna, nessa Resolução, no artigo $5^{\circ}$, que estabelece os fatores relacionados com a matéria ou disciplina para a qual era feita a indicação e que seriam considerados além da qualificação básica. $\mathrm{O}$ que se depreende da leitura dessa legislação, em seu conjunto, é a inexistência, na sua vigência, de uma exigência expressa da pós-graduação como pressuposto para o exercício do magistério superior, embora fosse ela bastante valorada para que a indicação pudesse ser efetivada. ${ }^{5}$

\footnotetext{
3 A palavra "lente", à época da edição da lei que criou os cursos de Direito no Brasil, era utilizada para designar o professor. BRASIL. Lei de 11 de agosto de 1827.

4 BRASIL. Conselho Federal de Educação (CFE). Resolução no 20/1977.

5 BRASIL. Conselho Federal de Educação (CFE). Resolução no 20/1977.
} 
No que se refere à norma vigente, contemporaneamente é ela expressa no sentido de que "a preparação para o exercício do magistério superior far-se-á em nível de pós-graduação". ${ }^{6}$ Se a preparação para o exercício do magistério superior se realiza no âmbito da pós-graduação, como diz o texto, não há como atribuir outro sentido à norma que não seja o da exigência de formação nesse nível para que a docência possa ser exercida em curso superior. Nesse sentido, o dispositivo da LDB leva a uma necessária profissionalização para o exercício do magistério superior, trazendo inegável contribuição para o aprimoramento da educação brasileira.

Mas a norma contida na LDB vai além. Estabelece que essa formação dever-se-á dar "prioritariamente em programas de mestrado e doutorado". ${ }^{7}$ Como se sabe, a pós-graduação contempla dois níveis:

a) os programas de pós-graduação lato sensu (onde se destacam as especializações); e

b) os programas de pós-graduação stricto sensu (mestrado e doutorado). A LDB não restringe a formação para o magistério superior aos cursos stricto sensu, permitindo, ainda que em caráter excepcional, a sua formação em cursos lato sensu. Diz-se excepcional, porque a norma estabelece que, prioritariamente, a preparação deverá ocorrer em programas de mestrado ou doutorado. Nesse sentido, objetiva que, gradativamente, todos os professores do ensino superior possuam formação em nível de mestrado ou doutorado.

A única exceção contida na LDB refere-se aos profissionais que possuam o reconhecimento do notório saber. Mas esse, segundo o que dispõe o parágrafo único do artigo 66, só pode ser concedido por "universidade com curso de doutorado em área afim". ${ }^{8}$ Ressalte-se que, embora não contemplada expressamente no texto legal, outra situação de exceção se mantém, tendo em vista constituir direito adquirido: o direito ao exercício do magistério superior, nas disciplinas para as quais obtiveram parecer favorável, daqueles professores que, sem possuírem curso de pós-graduação, foram indicados na forma da Resolução CFE $n^{\circ}$ 20/1977 e tiveram seus nomes aprovados.

6 BRASIL. Lei $n^{\circ}$ 9.394/1996 (LDB).

7 BRASIL. Lei $n^{\circ}$ 9.394/1996 (LDB).

8 BRASIL. Lei $n^{\circ}$ 9.394/1996 (LDB). 


\section{A incidência temporal da exigência de titulação acadêmica}

Pode-se afirmar, sem nenhuma dúvida no campo jurídico, que a norma contida no artigo 66 da LDB é autoaplicável (ou seja, independe de regulamentação), tendo incidência imediata a partir da vigência da nova legislação educacional brasileira. Não cabe aqui a aplicação do prazo de oito anos, previsto no artigo 88 , parágrafo $2^{\circ}$, tendo em vista que esse tem abrangência expressa, qual seja alcançar o percentual de um terço de professores com mestrado ou doutorado (art. 52, inc. II) e um terço de professores com tempo integral (art. 52, inc. III), no corpo docente das universidades. ${ }^{9}$

Nesse sentido, a partir da entrada em vigor da nova LDB, ninguém poderia ter passado a exercer o magistério superior sem que possuísse, no mínimo, curso de especialização (pós-graduação lato sensu), na modalidade acadêmico. Apenas poderiam ter continuado em sala de aula os professores não titulados que possuíssem direito adquirido à época da edição da referida lei.

O Conselho Nacional de Educação (CNE), no Parecer CES/CNE ${ }^{\circ}$ 1.070/1999, abre uma possibilidade de exceção, ao mencionar que a lei exige:

[...] que os docentes nas instituições de nível superior sejam formados em cursos de pós-graduação stricto sensu ou lato sensu.

A presença de docentes sem especialização pode ser aceita, excepcionalmente, mediante compromisso da instituição no sentido de, em prazo pré-determinado, assegurarem que os docentes adquiram a qualificação mínima. ${ }^{10}$ (grifo do autor).

Destaque-se que nesse parecer, em nenhum momento, o CNE questiona a exigência da pós-graduação ou abre a possibilidade do exercício perene do magistério superior sem essa titulação. Apenas levanta a possibilidade de, em caráter excepcional, aceitar-se a presença de docente sem formação em nível de pós-graduação, devendo, entretanto, a instituição comprometer-se em lhe assegurar, em prazo determinado, a qualificação mínima.

9 BRASIL. Lei no 9.394/1996 (LDB).

${ }^{10}$ BRASIL. Conselho Nacional de Educação (CNE). Câmara de Ensino Superior (CES). Parecer CES/CNE $n^{\circ}$ 1.070/1999. 
Também é necessário destacar o fato de que é ele apenas um parecer, nunca tendo dado origem a uma resolução que regulamentasse essa matéria; teria, nesse sentido, apenas caráter orientador e não normativo.

Ou seja, essa possibilidade seria excepcional e aplicável unicamente a cursos já existentes. Em nenhuma hipótese poderia ser transposta para cursos novos, ainda não reconhecidos, ou para projetos de cursos a serem autorizados. E mesmo que tivesse caráter normativo, o que não ocorreu, seria transitória, pois a partir do momento em que houver número de titulados suficientes para o exercício do magistério superior, nas vagas existentes, não mais poderá se permitir, nem como excepcionalidade, o exercício do magistério superior por quem não possuir, no mínimo, curso de especialização. E é bom lembrar, novamente, que o objetivo, evidenciado na expressão prioritariamente contida na norma, é de que se chegue a um momento em que todos os professores de cursos superiores possuam mestrado ou doutorado.

\section{A abrangência da expressão "preparação para o exercício do magistério superior"}

Em relação a esse aspecto é necessário destacar, em um primeiro momento, que a norma em análise neste artigo encontra-se situada dentro do Título IV da LDB, que possui a denominação "Dos Profissionais da Educação". "11 Também que o artigo 61 desse Título, cujo conteúdo é geral e se aplica a todos os níveis de exercício magistério, assim dispõe:

A formação de profissionais da educação, de modo a atender aos objetivos dos diferentes níveis e modalidades de ensino e às características de cada fase do desenvolvimento do educando, terá como fundamentos:

I - a associação entre teorias e práticas, inclusive mediante a capacitação em serviço;

II - aproveitamento da formação e experiências anteriores em instituições de ensino e outras atividades. ${ }^{12}$ (grifo do autor).

11 BRASIL. Lei $n^{o}$ 9.394/1996 (LDB).

${ }_{12}$ BRASIL. Lei $n^{0}$ 9.394/1996 (LDB). 
Percebe-se, tanto da colocação tópica (Dos Profissionais da Educação) da norma contida no artigo 66, em análise, quanto da expressão que introduz o primeiro artigo desse Título, [...] formação de profissionais da educação [...], que quando se utiliza a expressão "preparação para $o$ exercício do magistério superior" $" 13$ se está, em realidade, tratando da profissionalização da docência em nível do ensino superior.

E para a profissionalização para a docência em nível de conteúdos e habilidades, com dupla abrangência, é necessário:

a) a formação didático-pedagógica; e

b) o domínio dos conteúdos das disciplinas a serem ministradas. Com relação ao segundo desses elementos, maior referência não se faz aqui necessária. A problemática maior se coloca com relação ao primeiro.

Embora a atual legislação que trata, no Brasil, da pós-graduação (Resoluções CES/CNE $n^{\circ} 1 / 2001^{14}$ e $n^{\circ} 1 / 2007^{15}$ ) não indique expressamente, em nenhum momento, a necessidade de incluir, quer seja na pós-graduação lato sensu, ${ }^{16}$ quer seja na pós-graduação stricto sensu, atividades voltadas à formação didático-pedagógica, essa exigência decorre, necessariamente, do objetivo institucional desses cursos, em sua configuração acadêmica, qual seja o de formar docentes e pesquisadores. ${ }^{17}$

13 BRASIL. Lei no 9.394/1996 (LDB).

14 BRASIL. Conselho Nacional de Educação (CNE). Câmara de Ensino Superior (CES). Resolução CNE/CES no 1/2001.

15 BRASIL. Conselho Nacional de Educação (CNE). Câmara de Ensino Superior (CES). Resolução CNE/CES no 1/2007.

16 Nesse sentido, a Resolução CES/CNE n 1/2001 rompeu com a tradição histórica das suas antecessoras (Resolução CFE n 12/83 e Resolução CES/CNE nº 03/99), quando deixou de exigir, expressamente, a presença de disciplinas didático-pedagógicas nos cursos de Especialização voltados à formação para o exercício do magistério superior. A Resolução CES/CNE n ${ }^{\circ}$ 1/2007 que a modificou parcialmente manteve a omissão ao regulamentar especificamente a pós-graduação lato sensu. A ausência dessa exigência, de forma expressa, entretanto não a elimina, tendo em vista a finalidade a que se destina o Curso, qual seja a de formar profissionais para o exercício do magistério superior.

17 No campo acadêmico e institucional, tem sido imensa a discussão sobre a pósgraduação acadêmica e a profissional, em especial sobre a distinção entre o mestrado acadêmico e o profissional. Sobre essa matéria, recomenda-se a leitura, dentre outros, dos seguintes documentos e textos: 
Em outras palavras, o enfoque acadêmico, presente através de atividades dirigidas à formação didático-pedagógica, é obrigatório em todo e qualquer curso de pós-graduação que objetive preparar para o exercício do magistério superior. Sem o cumprimento desse pré-requisito, não estará formando profissionais da educação e seus egressos não poderão exercer o magistério superior. ${ }^{18}$

\section{A exigência específica de percentual de titulação para os docentes das universidades}

No mês de dezembro de 2004, a LDB completou oito anos. E esse foi o prazo previsto nas suas disposições transitórias (art. 88, $\S 2^{\circ}{ }^{\circ}{ }^{19}$ para que as Universidades cumprissem duas das exigências constantes do seu artigo $52,{ }^{20}$ especificamente nos incisos I e II:

a) possuir, no mínimo um terço do corpo docente com titulação acadêmica de mestrado ou doutorado; e

b) possuir, no mínimo um terço do corpo docente em regime de tempo integral. ${ }^{21}$

Nesse sentido, a partir de 2005, duas realidades são plenamente exigíveis em termos da titulação dos professores universitários:

18 Destaque-se que quando o artigo 65 da LDB estabelece que " $A$ formação docente, exceto para a educação superior, incluirá prática de ensino de, no mínimo, trezentas horas", ela não busca dispensar a pós-graduação dos conteúdos e habilidades voltados à necessária formação didático-pedagógica, mas tão somente dispensá-la da carga horária mínima de 300 horas, irreal para esse nível de ensino.

19 Art. 88. [...]

$\S 2$. O prazo para que as universidades cumpram o disposto nos incisos II e II do art. 52 é de oito anos.

20 Art. 52. As universidades são instituições pluridisciplinares de formação dos quadros profissionais de nível superior, de pesquisa, de extensão e de domínio e cultivo do saber humano, que se caracterizam por:

I $[\ldots]$;

II um terço do corpo docente, pelo menos, com titulação acadêmica de mestrado ou doutorado;

III um terço do corpo docente em regime de tempo integral.

21 BRASIL. Lei $n^{\circ}$ 9.394/1996 (LDB). 
a) que todos os professores em exercício no ensino superior (independentemente da espécie de instituição) tenham cursado e concluído, com aprovação, um curso pós-graduação credenciado (no mínimo a especialização); e

b) que, no mínimo, um terço dos docentes das universidades possuam pós-graduação stricto sensu (mestrado ou doutorado); ou, dito de outra forma, que nas universidades no máximo dois terços dos professores possuam apenas a pós-graduação lato sensu.

Paralelamente à exigência relativa à titulação, também se torna obrigatório, a partir de 2005, o mínimo de um terço de professores de tempo integral nas universidades. E é o Decreto $\mathrm{n}^{0}$ 5.773/2006 que estabelece o conceito de professor de tempo integral:

Art. 69. O exercício de atividade docente na educação superior não se sujeita à inscrição do professor em órgão de regulamentação profissional.

Parágrafo único. O regime de trabalho docente em tempo integral compreende a prestação de quarenta horas semanais de trabalho na mesma instituição, nele reservado o tempo de pelo menos vinte horas semanais para estudos, pesquisa, trabalhos de extensão, planejamento e avaliação.22

Diante do exposto, conclui-se, relativamente à questão da titulação exigida para os professores das universidades:

a) que todos os seus docentes devam possuir pós-graduação (lato ou stricto sensu) visto que essa regra se aplica a todas as Instituições de Ensino Superior (IES), independentemente de espécie;

b) que no mínimo um terço do seu corpo docente deva possuir pósgraduação stricto sensu (mestrado ou doutorado).

Além dessas exigências relativas à titulação aplica-se também às universidades a exigência que um terço de seu corpo docente possua tempo integral; essa exigência aplica-se unicamente às universidades. ${ }^{23}$

No que se refere às exigências que atingem as universidades, a interpretação deve ser no sentido de que esses percentuais mínimos

22 BRASIL. Presidência da República. Decreto no 5.773/2006.

${ }^{23}$ BRASIL. Lei $n^{o}$ 9.394/1996 (LDB). Art. 52, inc. II. 
atinjam todos os seus cursos e não apenas alguns. Ou seja, não basta cumpri-la relativamente ao conjunto do corpo docente; é necessário também cumpri-la em cada curso específico.

\section{Conclusão}

a) que a formação em nível de pós-graduação é exigência legal (portanto obrigatória) para o exercício do magistério superior em toda e qualquer IES;

b) que podem ser aceitos, para o exercício do magistério superior, cursos de pós-graduação lato sensu e stricto sensu, sendo a aceitação da especialização a exceção, e a exigência de mestrado ou doutorado, a regra;

c) que a norma contida no artigo 66 da LDB tem aplicação desde a sua edição, não sendo permitido o exercício do magistério superior por quem não possua, no mínimo, curso de pósgraduação lato sensu;

d) que para as universidades há exigência expressa de no mínimo um terço de docentes com titulação acadêmica de mestrado ou doutorado;

e) que a preparação para o exercício do magistério superior inclui, além do estudo dos conteúdos específicos das disciplinas ministradas, também a necessária preparação didático-pedagógica;

f) que o oferecimento de atividades destinadas à necessária preparação didático-pedagógica dos docentes do ensino superior é obrigatório em todos os cursos de pós-graduação que permitam o exercício dessa atividade profissional, tendo em vista a necessária interpretação finalística do disposto no artigo 66 da LDB.

\section{Referências}

BRASIL. Lei de 11 de agosto de 1827. Cria dois cursos de Ciências Jurídicas e Sociais, um na cidade de São Paulo e outro na de Olinda. Disponível em: $<$ http://www.planalto.gov.br/ccivil_03/revista/Rev_63/ Lei_1827.htm>. Acesso em: 19 ago. 2008. 
BRASIL. Lei $n^{\circ}$ 9.394, de 20 de dezembro de 1996 (LDB). Estabelece as diretrizes e bases da educação nacional. Disponível em: $<\mathrm{http}: / / \mathrm{www}$. planalto.gov.br/ccivil_03/Leis/L9394.htm>. Acesso em: 19 ago. 2008.

BRASIL. Lei $n^{\circ}$ 10.861, de 14 de abril de 2004 (SINAES). Institui o Sistema Nacional de Avaliação da Educação Superior - SINAES e dá outras providências. Disponível em: <http://www.planalto.gov.br/ ccivil_03/_Ato2004-2006/2004/Lei/L10.861.htm>. Acesso em: 19 ago. 2004.

BRASIL. Presidência da República. Decreto $n^{-} 5.773$, de 15 de agosto de 2006. Regulamenta o art. 19 da Lei $n^{o}$ 10.696, de 2 de julho de 2003. Disponível em: <http://www.planalto.gov.br/ccivil_03/_Ato20042006/2006/Decreto/D5873.htm>. Acesso em: 19 ago. 2008.

BRASIL. Conselho Federal de Educação (CFE). Resolução no 20, de 26 de dezembro de 1977. Fixa normas para a indicação do corpo docente das Instituições de Ensino Superior. Disponível em: <http://www.prolei.inep. gov.br/exibir.do?URI=http $\% 3 \mathrm{~A} \% 2 \mathrm{~F} \% 2 \mathrm{Fwww}$.ufsm.br $\% 2 \mathrm{Fcpd} \% 2 \mathrm{Finep}$ \%2Fprolei\%2FDocumento\%2F-5494319900950584792>. Acesso em: 4 set. 2008.

BRASIL. Conselho Federal de Educação (CFE). Resolução no 12, de 6 de outubro de 1983. Fixa condições de validade dos certificados de cursos de aperfeiçoamento e especialização para o Magistério Superior, no Sistema Federal. Disponível em: <http://www.prolei.inep.gov.br/exibir. do?URI=http $\% 3 \mathrm{~A} \% 2 \mathrm{~F} \% 2 \mathrm{Fwww}$. ufsm.br $\% 2$ Fcpd $\% 2$ Finep $\% 2$ Fprolei $\% 2$ FDocumento\%2F-1321521969810027927>. Acesso em: 4 set. 2008.

BRASIL. Conselho Nacional de Educação (CNE). Câmara de Ensino Superior (CES). Parecer CES/CNE n 1.070, de 23 de novembro de 1999. Critérios para autorização e reconhecimento de cursos de Instituições de Ensino Superior. Disponível em: $<$ http://portal.mec.gov.br/cne/arquivos/ pdf/pces1070_99.pdf>. Acesso em: 4 set. 2008.

BRASIL. Conselho Nacional (CNE). Câmara de Ensino Superior (CES). Parecer CNE/CES nº 82, de 10 de abril de 2008. Revisão dos fundamentos e das normas para credenciamento especial de Instituições não Educacionais para oferta de cursos de especialização. Disponível em: <http://portal.mec.gov.br/cne/arquivos/pdf/2008/pces082_08.pdf>. Acesso em: 4 set. 2008. 
BRASIL. Conselho Nacional de Educação (CNE). Câmara de Ensino Superior (CES). Resolução CNE/CES no 3, de 5 de outubro de 1999. Fixa condições de validade dos certificados de cursos presenciais de especialização. Disponível em: <http://portal.mec.gov.br/cne/arquivos/ pdf/rces03_99.pdf>. Acesso em: 4 set. 2008.

BRASIL. Conselho Nacional de Educação (CNE). Câmara de Ensino Superior (CES). Resolução CNE/CES no 1, de 3 de abril de 2001.

Estabelece normas para o funcionamento de cursos de pós-graduação. Disponível em: <http://portal.mec.gov.br/cne/arquivos/pdf/rces01_01. pdf $>$. Acesso em: 4 set. 2008.

BRASIL. Conselho Nacional de Educação (CNE). Câmara de Ensino Superior (CES). Resolução CNE/CES no 1, de 8 de junho de 2007.

Estabelece normas para o funcionamento de cursos de pós-graduação lato sensu, em nível de especialização. Disponível em: <http://portal.mec.gov. br/cne/arquivos/pdf/rces001_07.pdf>. Acesso em: 4 set. 2008.

BRASIL. Ministério da Educação (MEC). CAPES. Portaria 80, de 16 de dezembro de 1998. Dispõe sobre o reconhecimento de mestrados profissionais... Disponível em: < http://www.capes.gov.br/export/sites/ capes/download/legislacao/Portaria_CAPES_080_1998.pdf $>$. Acesso em: 4 set. 2008.

BRASIL. Ministério da Educação (MEC). CAPES. Área: Direito. Critérios de implantação mestrado e doutorado acadêmico / mestrado profissional, de março de 2007. Disponível em: <http://www.capes.gov. br/export/sites/capes/download/avaliacao/Direito_MDA.pdf $>$. Acesso em: 4 set. 2008 .

BRASIL. Ministério da Educação (MEC). CAPES. [Textos e documentos sobre mestrado profissional]. Disponível em: <http://www.capes.gov.br/ result.jsp?index $=$ capes $\&$ field $=$ title $\&$ field $=$ keywords $\&$ field $=$ description $\&$ field $=$ content $\&$ query $=$ mestrado + profissional $>$. Acesso em: 4 set. 2008 .

RIBEIRO, Renato Janine. Mestrado profissional, mestrado acadêmico e doutorado. Disponível em: <http://www.anpg.org.br/veja_2007/ mestrado_prof.htm>. Acesso em 4 set. 2008.

RIBEIRO, Renato Janine. Ainda sobre o Mestrado Profissional. $<$ http:// www2.capes.gov.br/rbpg/portal/conteudo/Deb_Artigo4_n6.pdf $>$. Acesso em: 4 set. 2008 . 